Cite as: Codish, D., \& Ravid, G. (2014). Academic course gamification: The art of perceived playfulness. Interdisciplinary Journal of E-Learning and Learning Objects, 10, 131-151. Retrieved from http://www.ijello.org/Volume10/IJELLOv10p131-151Codish893.pdf

\title{
Academic Course Gamification: The Art of Perceived Playfulness
}

\author{
David Codish and Gilad Ravid \\ Ben-Gurion University of the Negev, Beer-Sheba, Israel
}

\author{
codishd@post.bgu.ac.il; rgilad@bgu.ac.il
}

\begin{abstract}
Gamification in education is being used as a way to increase student engagement and learning. While carrying a big promise, little is known about how students with different personalities, specifically extraverts and introverts, are influenced by game elements and mechanics: knowledge that is essential to ensure that implementing gamification will not disengage some students. In two quasi-experiments performed in an academic course, students $(n=102 ; n=58)$ were faced with the immediate feedback game mechanics such as points, rewards, and badges, and comparative feedback mechanics such as leaderboards and progress bars. The perceived playfulness from the implementation was measured and a Partial Least Squares (PLS) analysis was performed measuring the relations between these elements and the way they increase the perceived playfulness throughout the semester. A moderation analysis was performed examining how extraverts and introverts perceive each implementation. Our results show that in both cases there were significant moderating effects between game mechanics and perceived playfulness. More specifically, the effect of leaderboards on perceived playfulness was higher for introverts and was negative for extraverts, meaning that implementing leaderboards may disengage extraverts. These results are important for gamification researchers who are looking at how different personalities derive perceived playfulness, based on different game mechanics and to educators who plan to include game elements in their courses.
\end{abstract}

Keywords: Gamification, Personality, Extraversion, Introversion, Game mechanics, Perceived Playfulness

\section{Background}

The inclusion of ludic elements into information systems and business processes is becoming

Material published as part of this publication, either on-line or in print, is copyrighted by the Informing Science Institute. Permission to make digital or paper copy of part or all of these works for personal or classroom use is granted without fee provided that the copies are not made or distributed for profit or commercial advantage AND that copies 1) bear this notice in full and 2) give the full citation on the first page. It is permissible to abstract these works so long as credit is given. To copy in all other cases or to republish or to post on a server or to redistribute to lists requires specific permission and payment of a fee. Contact Publisher@InformingScience.org to request redistribution permission. commonplace as a means of engaging users and increasing system acceptance (Deterding, Sicart, Nacke, O'Hara, \& Dixon, 2011; Huotari \& Hamari, 2011; Zichermann \& Cunningham, 2011). Traditionally, hedonic and utilitarian systems were treated and researched as separate entities (Van der Heijden, 2004), but in the past years they are converging into a field called gamification which is defined as the use of game

\section{Editor: Janice Whatley}

An earlier, shorter version of this paper was presented at the Chais conference 2014, in Raanana, Israel, and included in Y. Eshet-Alkalai, A. Caspi, N. Geri, Y. Kalman, V. Silber-Varod, \& Y. Yair (Eds.), Proceedings of the Chais Conference for the Study of Innovation and Learning Technologies 2014: Learning in the Technological Era. Raanana: The Open University of Israel. 
design elements in non-game contexts such as, but not limited to, workplaces (Deterding, Dixon, Khaled, \& Nacke, 2011). In the context of education, it can be viewed as the inclusion of game elements into the traditional classroom, existing training materials, and the Learning Management Systems (LMS).

Game elements are also referred to as game mechanics and dynamics. Game mechanics are defined as "constructs of rules and feedback loops intended to produce enjoyable gameplay. They are the building blocks that can be applied and combined to gamify any non-game context" (Gamification.org, 2012). Most common game mechanics are Points, Badges, and Leaderboards (PBL) (Antin \& Churchill, 2011; Narasimhan, Chiricescu, \& Vasudevan, 2011; Werbach \& Hunter, 2012; Zichermann \& Cunningham, 2011), but there are many additional mechanics (Schonfeld, 2010) that exist in games and can be designed into systems and processes. Dynamics are the run-time behavior of the mechanics acting on player inputs and each other's outputs over time (Hunicke, LeBlanc, \& Zubek, 2004), and can be viewed as the pattern of play that is generated by the application of specific mechanics and in response to other player interactions or expected interactions (Brathwaite \& Schreiber, 2009). Dynamics cannot be programmed into a gamified solution but the use of the right mechanics can improve the chance of the dynamic occurring. Typical dynamics found in games are constraints, emotions, narrative, progression, and relationships (Werbach \& Hunter, 2012).

Games as a means of learning have been studied extensively, and, while they have been found to mostly increase learning and understanding, there are still several cases where they did not (Hays, 2005; Ke, 2009; Vogel et al., 2006). The recommendations from these studies are that "...games should be used as adjuncts and aids, not as stand-alone instructions" (Hays, 2005).

An important distinction exists between Game Based Learning (GBL) and gamification. GBL provides students with games that have an educational objective that are achieved through the game play (Kim, Park, \& Baek, 2009). These games can supplement direct teaching or replace it, but it is clearly a game. The essence of gamification is that it occurs in a non-game context; therefore, it would be applied in such a way that would not change the existing practice of learning and instead focus on making it more engaging and challenging for students. An example that is most commonly used in education is granting badges to students who perform well in class, which in return increases their motivation as well as others in the class.

There is an increasing number of case studies and research dealing with gamification in general (Hamari, Koivisto, \& Sarsa, 2014) and in educational contexts in particular (Barata, Gama, Jorge, \& Goncalves, 2013; Sheldon, 2011). The objectives of gamification in these educational context studies has been to increase student motivation to attend class, download course material, participate in on-line discussions, and complete extra assignments. While the majority of studies report overall positive results as a result of adding game elements, not all have exhibited these results. Some of these differences can be explained by design and context, but even within the studies themselves there are differences in how individuals are impacted by gamification which can be explained by personality differences (Hamari, 2013; Hamari, et al., 2014).

Different personality theories exist focusing on personality types and needs, but for the sake of this paper we will focus on the Big Five model (also called the Five Factor Model - FFM) which has been proposed as trait theory (McCrae \& Costa, 1989) and is widely accepted in the field. FFM posits that individuals can be measured on the following five traits: neuroticism, extraversion, openness, agreeableness, and consciousness (McCrae \& John, 1992).

This study takes a specific view of the personality trait of extraversion and seeks to understand how people with high levels of extraversion and people with high levels of introversion perceive different game mechanics in a gamification setting, and whether they perceive the entire solution to be playful. Studies show that extraverts are more likely to be achievement oriented and seek 
hedonic values (Roccas, Sagiv, Schwartz, \& Knafo, 2002) and have learning styles that promote group activities, talking out loud, and learning through interactions (Lawrence, 1993). Introverts, on the other hand, prefer to reflect first and act later, work privately, present their work in a way that lets them keep their privacy (Lawrence, 1993), prefer asynchronous communication, and in online settings would typically have higher levels of usage (Amichai-Hamburger, Wainapel, \& Fox, 2002; Yeung, Read, \& Schmid, 2012).

There is limited research on the extraversion trait moderation effects of game mechanics, a gap that this study aims to fill. Based on Eysenck's work, Gray has found that extraverts are motivated by the availability of a reward to be achieved, whereas introverts are motivated by the avoidance of punishment (Gray, 1970), a finding that was also repeated in classroom settings (McCord \& Wakefield Jr, 1981). It is therefore hypothesized that extraversion will moderate the relation between rewards and perceived playfulness.

H1: Extraversion will moderate the effect between rewards and perceived playfulness such that for extraverts they have a stronger positive effect

We relate progress bars to the goal setting theory (Locke, Shaw, Saari, \& Latham, 1981) since they are a form of "summary feedback that reveals progress in relation to their goals " (Locke \& Latham, 2002, p. 708). Goal-setting theory studies looking at the moderating effects of extraversion did not find such moderation (Barrick, Mount, \& Strauss, 1993; Judge \& Ilies, 2002), therefore we do not expect to see such moderation between progress bars and perceived playfulness.

$\mathrm{H} 2$ : Extraversion will not moderate the effect between progress bars and perceived playfulness

Points and leaderboards often work together, i.e., leaderboards present the points accumulated by the user, but leaderboards can also serve to present progress or badges earned. Leaderboards promote competition since they are a comparative mechanic, which is a game dynamic that should be considered consciously, as leaderboards can change behavior in both good and bad ways (Costa, Wehbe, Robb, \& Nacke, 2013; Zichermann \& Cunningham, 2011). Hyper-competitions reflect a competition where there is a need to win at any cost, whereas personal development competitions are situations that are viewed by individuals as competition that promote personal growth. In both cases, as in cooperation games, it has been found that participation is positively correlated with extraversion (Ross, Rausch, \& Canada, 2003; Ryckman, Thornton, Gold, \& Collier, 2011), therefore we hypothesize that extraverts would perceive points and leaderboards in a positive way and thus derive higher playfulness from them.

H3: Extraversion will moderate the effect between points and leaderboard with perceived playfulness, such that for extraverts they have a stronger positive effect

The use of badges, or virtual achievements, is popular in on-line systems and have been proven successful in increasing user participation (Anderson, Huttenlocher, Kleinberg, \& Leskovec, 2013; Denny, 2013; Hakulinen, Auvinen, \& Korhonen, 2013) . Badges represent different needs, such as goal setting, instruction, reputation, status/affirmation, and group identification (Antin \& Churchill, 2011), depending on the type of badge used. For a system that applies several different badges, we would expect that there is no moderating extraversion effect and that they would be positively related with perceived playfulness.

H4: Extraversion will not moderate the effect between badges and perceived playfulness

LMSs provide educators with the ability to combine online experiences that supplement the classroom teaching and provide additional channels of communication with students. Gamifying a traditional academic classroom using a LMS has several of the characteristics that would promote learning styles that are more suitable for introverts by providing an ability to reflect and to com- 
municate at their own pace. On the other hand, since there is no anonymity and classmates know each other in person, they can also promote extraversion learning styles such as group activities and achievement.

Several game mechanics exist and every given solution may include them in a different way, still, there are common feedback game mechanics, such as points, rewards, and badges, and presentation mechanics, such as leaderboards and progress bars, that are typical in many of the systems. Our model (Figure 1) includes these feedback and presentation mechanics, leading to the perceived playfulness of the system.

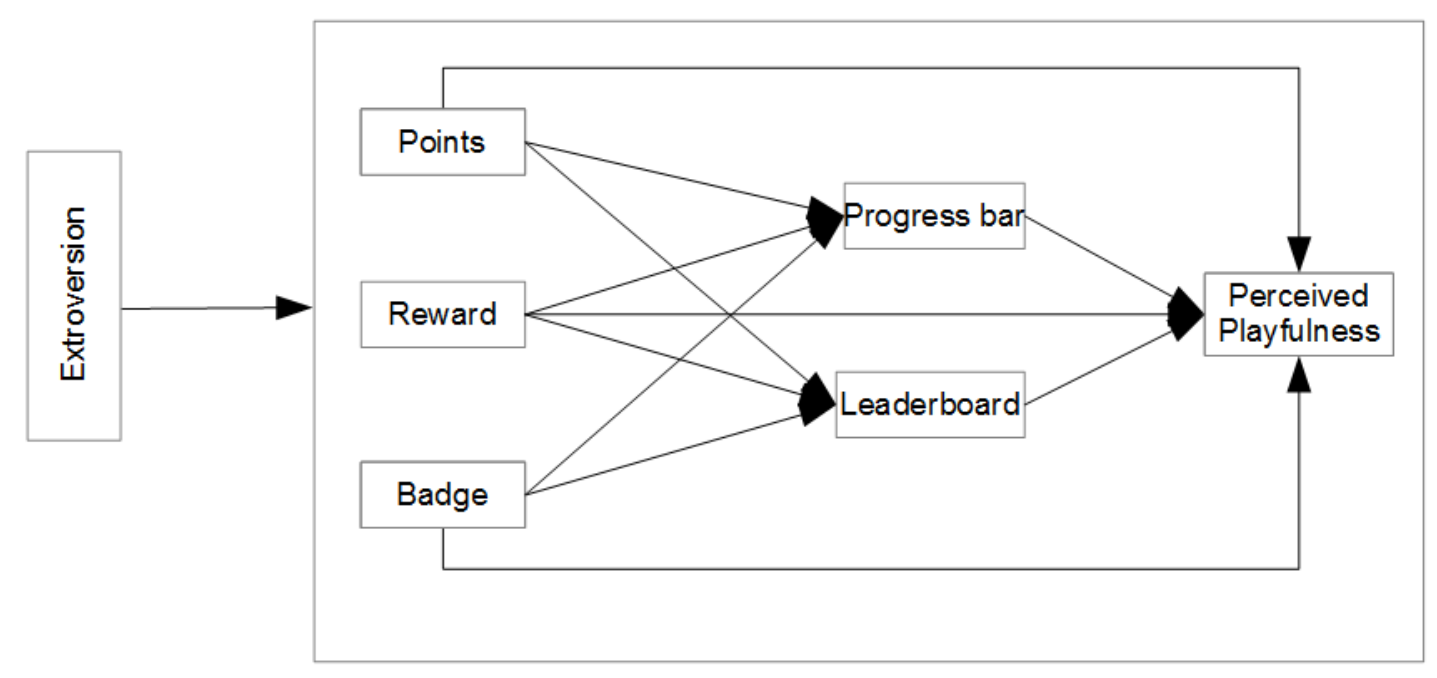

Figure 1 - Research Model

Our research questions are aimed at understanding personality differences in the perceived playfulness from a gamification implementation in an academic course setting. Specifically, is there a difference in how introverts and extraverts perceive the playfulness of a gamified solution and what are the relations between the feedback mechanics and the presentation mechanics and are they moderated by the extraversion trait?

\section{Methodology}

To test the model, two Quasi-Experiments (QE1 and QE2) were performed by applying gamification elements to an undergraduate engineering course, with the majority of students in their third year out of four, majoring in Industrial Engineering and Management. In both cases the same course was used (Software analysis and design). Both courses included similar elements with the distinction of the first course using a manual tracking system and the second course using a fully automated LMS for tracking. The second quasi-experiment was performed in the subsequent semester (Spring 2013 and Fall 2014 semesters) with different students but with the same characteristics as in QE1.

In QE1 the points game mechanic was operationalized as the desire to receive feedback in the form of grade points (I prefer to receive a numeric grade over a pass/fail grade on all tasks in the course), and in QE2 as the desire to receive points for course contribution. Rewards were operationalized as the desire to receive physical rewards (I enjoy winning prizes) and badges as a means of receiving virtual feedback/reward (I'm willing to put in extra effort in order to gain a trophy). Leaderboards are a form of comparative feedback (It's important for me to know my position compared to other classmates), and progress bars refers to individual feedback (It's im- 
portant for me to know what I need to do to progress). For the full list of items used to measure each construct, see Appendix A.

At the beginning of each semester, students completed a personality questionnaire using the revised FFM questionnaire (Goldberg, 1992) which includes 50 items (see Appendix B). Towards the end of the semester, students were asked about the perceived enjoyment from different game mechanics such as those presented in the course, and at the end of the semester, students were asked about the playfulness derived from specific activities in the course, using a nine item scale adapted from Moon and Kim (2001). All items in all questionnaires were measured on a Likert 15 scale.

To test the research model (Figure 1), we used Partial Least Squares (PLS) structural equation modeling. PLS is a well-established statistical method which is most suitable for cases where (a) the research has an exploratory nature and a relatively small sample size (Henseler, Ringle, \& Sinkovics, 2009) and (b) the model has an interaction nature (Endler \& Parker, 1992). The software used was SmartPLS version 2.0M3 (Ringle, Wende, \& Will, 2005).

Since there is no specific value on the extraversion scale that determines whether one is an extravert or an introvert, this scale was standardized and students with $z \geq 0$ were considered as extraverts while students with $\mathrm{z}<0$ were considered as introverts. This was also done due to the limited sample size. In each quasi-experiment, the model was executed three times. First execution was performed on the entire sample, and the next two on extraverts and introverts. A multi-group analysis was then performed to detect any moderating effects.

\section{Quasi-Experiment 1}

The first quasi-experiment used a semester long project activity in the course. As part of the course requirements, students are required to complete a semester long project in which they select an organization of their choice, identify a business problem, and go through the analysis, design, and development of a solution to that problem. To add gamification to the project, a narrative of a software development house was used. Students were told that, as often happens in real life, their deliverables from the first part of the project where they serve as business analysts, will be handed over to a different team of system analysts who will continue their work from that point, and they will receive the deliverables of a different team. This will be repeated at the end of the second part of the project, where they will transfer their work to a team of developers. Each team for each phase of the project received quantitative feedback from the course staff in the form of points and qualitative verbal feedback from the team they handed their project over to. In addition to the feedback described, best project badges were provided in the form of an email sent to the specific projects and class wide appraisal for good work on projects was delivered in class. Students were aware of the grades and feedback other teams received, and their location compared to those teams resembling, while not in an automated manner, leaderboard and progression mechanics.

Tracking student accomplishments and game mechanics was performed without a formal information system. The course was managed, as other courses were, using the Britannica Knowledge Systems' LMS, but no specific changes were made to the system to support the gamification effort. All tracking was done using a simple spreadsheet to track progress and grades of students.

Throughout the course four surveys were administered to students in which they were questioned, among other topics, about their attitudes towards the actual use of different game mechanics in the course and their perceived playfulness from the gamified project (see Appendix A and B for survey items). The first survey was manually completed by students and the remaining surveys were completed using Google docs. For each questionnaire completed, students receive 0.5 credit points in the course. 


\section{Results}

Descriptive statistics of the measured values are presented in Table 1. The course included 133 students; 102 completed all surveys and were included in final analysis (76.7\%). Of the students responding, 58 were female and 44 were male. Students were all in the age range of 23-30 years.

Table 1. QE1 - Descriptive Statistics

\begin{tabular}{|l|c|c|c|c|c|}
\hline & \# ite ms & Minimum & Maximum & Me an & $\begin{array}{c}\text { Std. } \\
\text { Deviation }\end{array}$ \\
\hline Points & 2 & 2 & 10 & 4.75 & 2.10 \\
\hline Leaderboard & 6 & 8 & 30 & 20.10 & 5.51 \\
\hline Progress bar & 4 & 8 & 20 & 16.14 & 2.76 \\
\hline Badge & 4 & 6 & 20 & 12.65 & 3.46 \\
\hline Playfulness & 6 & 6 & 24 & 13.92 & 4.75 \\
\hline Reward & 4 & 4 & 20 & 13.59 & 3.04 \\
\hline Extraversion & 10 & 16 & 49 & 35.01 & 7.01 \\
\hline
\end{tabular}

Internal and convergent validity indices have been examined for the full model and each subset. Cronbach's alpha values are above the desired 0.7 index with the exception of the points construct that is 0.67 for the full model which is deemed acceptable by us due to the explorative nature of this study. Average Variance Extracted (AVE) and cross correlations are presented in Table 2 showing acceptable values with AVE $>0.5$ for the full model and cross loadings all significantly higher on their construct than on others. Introverts AVE for progress bar is slightly lower than 0.5 but still shares significantly more variance with its indicators than with other constructs.

Table 2. QE1 - Validity Indices: AVE, Cronbach's Alpha, and Cross Correlations

\begin{tabular}{|c|c|c|c|c|c|c|c|c|c|c|}
\hline & & AVE & $\begin{array}{l}\text { Composite } \\
\text { Reliability }\end{array}$ & $\begin{array}{l}\text { Cronbach's } \\
\text { Alpha }\end{array}$ & Badge & Leaderboard & Playfulness & Points & \begin{tabular}{|l|} 
Progress \\
bar
\end{tabular} & Reward \\
\hline \multirow{6}{*}{ ¿ } & Badge & 0.59 & 0.85 & 0.77 & 0.77 & & & & & \\
\hline & Leaderboard & 0.63 & 0.91 & 0.89 & 0.49 & 0.80 & & & & \\
\hline & Playfulness & 0.65 & 0.92 & 0.89 & 0.12 & 0.03 & 0.81 & & & \\
\hline & Points & 0.72 & 0.83 & 0.67 & 0.19 & 0.07 & 0.25 & 0.85 & & \\
\hline & Progress bar & 0.54 & 0.83 & 0.73 & 0.20 & 0.18 & 0.38 & 0.32 & 0.74 & \\
\hline & Reward & 0.56 & 0.84 & 0.75 & 0.50 & 0.32 & 0.14 & 0.17 & 0.30 & 0.75 \\
\hline \multirow{6}{*}{ 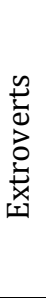 } & Badge & 0.60 & 0.85 & 0.78 & 0.77 & & & & & \\
\hline & Leaderboard & 0.62 & 0.91 & 0.88 & 0.42 & 0.79 & & & & \\
\hline & Playfulness & 0.67 & 0.92 & 0.90 & 0.11 & -0.10 & 0.82 & & & \\
\hline & Points & 0.70 & 0.82 & 0.62 & 0.24 & -0.03 & 0.29 & 0.84 & & \\
\hline & Progress bar & 0.57 & 0.84 & 0.75 & 0.28 & 0.19 & 0.46 & 0.40 & 0.76 & \\
\hline & Reward & 0.59 & 0.85 & 0.77 & 0.37 & 0.29 & 0.10 & 0.16 & 0.43 & 0.77 \\
\hline \multirow{6}{*}{ 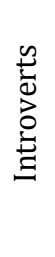 } & Badge & 0.53 & 0.82 & 0.71 & 0.73 & & & & & \\
\hline & Leaderboard & 0.66 & 0.92 & 0.90 & 0.63 & 0.81 & & & & \\
\hline & Playfulness & 0.64 & 0.91 & 0.89 & 0.17 & 0.21 & 0.80 & & & \\
\hline & Points & 0.72 & 0.83 & 0.72 & 0.10 & 0.18 & 0.21 & 0.85 & & \\
\hline & Progress bar & 0.48 & 0.78 & 0.71 & 0.05 & 0.14 & 0.37 & 0.31 & 0.69 & \\
\hline & Reward & 0.52 & 0.81 & 0.72 & 0.66 & 0.39 & 0.21 & 0.14 & 0.14 & 0.72 \\
\hline
\end{tabular}

${ }^{a}$ Squared root of the AVE are the bolded diagonal values 
A t-test was performed comparing the two groups against the different game mechanics and perceived playfulness (Table 3 ) showing that extraverts have a stronger enjoyment level from badges than introverts. No other significant difference existed.

Table 3. QE1 - T-test Comparing Extraversion and Introversion

\begin{tabular}{|l|c|c|c|c|c|}
\hline & \multicolumn{2}{|l|}{ Extroversion } & \multicolumn{2}{l|}{ Intraversion } & \\
\cline { 2 - 5 } & Mean & Std. dev. & Mean & Std. dev. & Sig. \\
\hline Badge & 13.49 & 3.58 & 11.73 & 3.11 & 0.01 \\
\hline Points & 4.85 & 2.12 & 4.63 & 2.09 & 0.61 \\
\hline Reward & 13.89 & 3.23 & 13.27 & 2.81 & 0.30 \\
\hline Progress bar & 16.42 & 2.86 & 15.84 & 2.66 & 0.29 \\
\hline Leaderboard & 19.92 & 5.80 & 20.29 & 5.23 & 0.74 \\
\hline Playfulness & 14.47 & 4.81 & 13.33 & 4.66 & 0.23 \\
\hline
\end{tabular}

Total effects between constructs were extracted using a bootstrap approach with 5000 resampling setting which is at the upper end of what researchers recommend (Lee \& Chen, 2010) and using number of observations as the number of cases (Hair, Ringle, \& Sarstedt, 2011). A comparative table showing these effects between the mechanics and perceived playfulness for each model is presented in Table 4. Several differences between introverts and extraverts are visible in this table, specifically leaderboard-perceived playfulness and points-leaderboard, which are negative for extraverts and positive though not significant for introverts, and the high relation between badges and leaderboard and between progress bar and perceived playfulness.

Table 4. QE1 - Comparative Total Effect

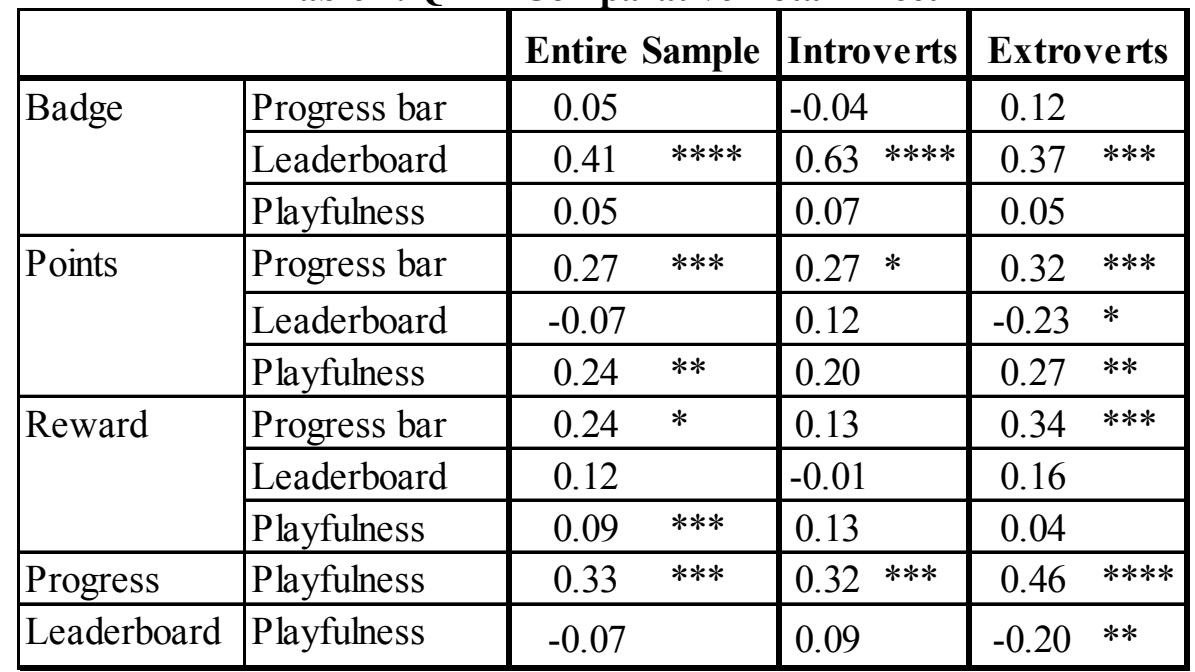

$* \mathrm{P}<0.1 ; * * \mathrm{p}<0.05 ; * * * \mathrm{p}<0.01 ; * * * * \mathrm{p}<0.001$

To test the significance of the differences between low and high extraversion, a multi-group analysis t-test was performed (Andreev, Heart, Maoz, \& Pliskin, 2009; Keil et al., 2000). Given the small sample size, standard errors are expected to be high, making it hard to identify group differences. For this reason, we will be treating $\mathrm{p}<0.1$ as significant. The results of this test are presented in Table 5, which highlights the fact that the relations with leaderboard are significantly different between introverts (higher) and extraverts (lower). 
Table 5. QE1 - Significance of Difference Based on Multi-Group Analysis

\begin{tabular}{|l|l|c|}
\hline \multirow{4}{*}{ Badge } & & $\begin{array}{c}\text { Group difference } \\
\text { (P value) }\end{array}$ \\
\hline \multirow{3}{*}{ Points } & Progress bar & 0.322 \\
\cline { 2 - 3 } & Leaderboard & $0.080 \quad *$ \\
\cline { 2 - 3 } & Playfulness & 0.396 \\
\hline \multirow{2}{*}{ Reward } & Progress bar & 0.387 \\
\cline { 2 - 3 } & Leaderboard & 0.027 \\
\cline { 2 - 3 } & Playfulness & 0.366 \\
\hline & Progress bar & 0.247 \\
\cline { 2 - 3 } & Leaderboard & 0.208 \\
\cline { 2 - 3 } & Playfulness & 0.355 \\
\hline Progress & Playfulness & 0.272 \\
\hline Leaderboard & Playfulness & 0.080 \\
\hline$*$ P $<0.1 ; * *$ & $<<0.05$ & \\
\hline
\end{tabular}

Last, the predictive relevance of the different models was tested using a blindfolding method in SmartPLS. $Q^{2}$ values were calculated for each of the models and are presented along with their $\mathrm{R}^{2}$ in Table 6 . All values are above 0.02 indicating low predictive relevance of the structural model, and in some cases they are above 0.15 indicating medium relevance (Hair, Hult, Ringle, \& Sarstedt, 2013).

Table 6. $Q E 1$ - $\mathbf{Q}^{2}$ Predictive Relevant Indices and $\mathbf{R}^{2}$

\begin{tabular}{|l|l|l|l|l|l|l|}
\hline & \multicolumn{2}{|c|}{ Full model } & \multicolumn{2}{c|}{ Introvert } & \multicolumn{2}{c|}{ Extrovert } \\
\hline & $\mathrm{R}^{\wedge} 2$ & $\mathrm{Q}^{\wedge} 2$ & $\mathrm{R}^{\wedge} 2$ & $\mathrm{Q}^{\wedge} 2$ & $\mathrm{R}^{\wedge} 2$ & $\mathrm{Q}^{\wedge} 2$ \\
\hline Progress bar & 0.167 & 0.087 & 0.101 & 0.025 & 0.314 & 0.183 \\
\hline Leaderboard & 0.214 & 0.144 & 0.411 & 0.3 & 0.196 & 0.133 \\
\hline Playfulness & 0.186 & 0.104 & 0.186 & 0.111 & 0.261 & 0.157 \\
\hline
\end{tabular}

\section{Quasi-Experiment 2}

The second quasi-experiment introduced the tracking of the various feedback mechanics through the Moodle LMS. The gamification in the course was not limited to the project in the course and included the entire course. Students were given points, badges, and rewards for specific activities in the course, such as participation in forums, answering knowledge quizzes, and logic quizzes. Two leaderboards existed presenting relative and absolute positioning of students. The first leaderboard presented the points that had no value to students, facilitating intrinsic motivation, and the second leaderboard presented points that granted students credit points, as part of their final grade. The top $25 \%$ of students on the leaderboard received 5 points in final grade (out of 100), the next $25 \%$ got 4 points, and so on, creating a competition between students.

Badges were provided for various achievements in the course, such as best project, innovative ideas, and helping other students, and were presented in the students' profile where they were visible to other students. Badges had no material value to students. Rewards were provided for specific activities in the form of a certificate students received automatically from the system. Each certificate carried a different material value and was redeemable by students. Examples of rewards were 3 days extra time for homework, extra help in project work, and a LinkedIn recommendation from course staff. 
Throughout the course, students completed similar questionnaires as in the first quasi-experiment, with some modifications that were required to increase reliability and validity. Additional wording changes were required to adapt to the nature of gamification from the project in QE1, to the entire course in QE2.

\section{Results}

Descriptive statistics of the measured values are presented in Table 7. The course included 74 students; 58 completed all surveys and were included in final analysis (78.4\%). Of the students responding, 28 were female and 30 were male. Students were all in the age range of 23-30 years.

Table 7. QE2 - Descriptive Statistics

\begin{tabular}{|c|c|c|c|c|c|}
\hline & \# ite ms & Minimum & Maximum & Mean & $\begin{array}{c}\text { Std. } \\
\text { De viation }\end{array}$ \\
\hline Points & 3 & 3 & 14 & 8.10 & 2.90 \\
\hline Reward & 4 & 4 & 18 & 11.48 & 3.57 \\
\hline Badge & 5 & 5 & 22 & 12 & 5 \\
\hline Progress bar & 4 & 5 & 20 & 13.88 & 3.51 \\
\hline Leaderboard & 3 & 3 & 15 & 8.84 & 3.11 \\
\hline Playfulness & 4 & 4 & 14 & 7.12 & 3.25 \\
\hline Extraversion & 10 & 20 & 48 & 33.03 & 6.08 \\
\hline
\end{tabular}

Internal and convergent validity indices have been examined for the full model and each subset and are presented in Table 8. Following the changes made to the questionnaire items from QE1, all Cronbach's alpha values are above the desired 0.7, all AVEs are above 0.5 and all cross loadings are higher on their construct than on others.

Table 8. QE2 - Validity Indices: AVE, Cronbach's Alpha, and Cross Correlations

\begin{tabular}{|c|c|c|c|c|c|c|c|c|c|c|}
\hline & & AVE & $\begin{array}{l}\text { Composite } \\
\text { Reliability }\end{array}$ & $\begin{array}{l}\text { Cronbach's } \\
\text { Alpha }\end{array}$ & Badge & Leaderboard & Playfulness & Points & \begin{tabular}{|l} 
Progress \\
bar
\end{tabular} & Reward \\
\hline \multirow{6}{*}{$\bar{z}$} & Badge & 0.59 & 0.87 & 0.81 & 0.77 & & & & & \\
\hline & Leaderboard & 0.69 & 0.87 & 0.77 & 0.62 & 0.83 & & & & \\
\hline & Playfulness & 0.75 & 0.92 & 0.89 & 0.39 & 0.25 & 0.87 & & & \\
\hline & Points & 0.67 & 0.86 & 0.75 & 0.24 & 0.32 & 0.27 & 0.82 & & \\
\hline & Progress bar & 0.60 & 0.85 & 0.78 & 0.58 & 0.67 & 0.14 & 0.23 & 0.77 & \\
\hline & Reward & 0.62 & 0.87 & 0.80 & 0.29 & 0.28 & 0.21 & 0.65 & 0.27 & 0.79 \\
\hline \multirow{6}{*}{ 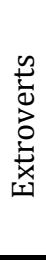 } & Badge & 0.62 & 0.89 & 0.84 & 0.79 & & & & & \\
\hline & Leaderboard & 0.68 & 0.86 & 0.75 & 0.69 & 0.82 & & & & \\
\hline & Playfulness & 0.75 & 0.92 & 0.89 & 0.55 & 0.25 & 0.87 & & & \\
\hline & Points & 0.69 & 0.87 & 0.78 & 0.30 & 0.41 & 0.23 & 0.83 & & \\
\hline & Progress bar & 0.67 & 0.89 & 0.83 & 0.64 & 0.73 & 0.34 & 0.32 & 0.82 & \\
\hline & Reward & 0.59 & 0.85 & 0.82 & 0.55 & 0.45 & 0.44 & 0.59 & 0.39 & 0.77 \\
\hline \multirow{6}{*}{ 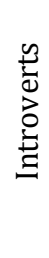 } & Badge & 0.58 & 0.87 & 0.80 & 0.76 & & & & & \\
\hline & Leaderboard & 0.74 & 0.89 & 0.82 & 0.55 & 0.86 & & & & \\
\hline & Playfulness & 0.75 & 0.92 & 0.89 & 0.22 & 0.27 & 0.86 & & & \\
\hline & Points & 0.62 & 0.83 & 0.71 & 0.13 & 0.29 & 0.25 & 0.79 & & \\
\hline & Progress bar & 0.55 & 0.83 & 0.73 & 0.49 & 0.59 & -0.15 & 0.11 & 0.74 & \\
\hline & Reward & 0.55 & 0.83 & 0.76 & 0.20 & 0.44 & -0.12 & 0.66 & 0.38 & 0.74 \\
\hline
\end{tabular}

${ }^{a}$ Squared root of the AVE are the bolded diagonal values 
A t-test comparing the different game mechanics between extraverts and introverts (Table 9) shows a slight difference on the rewards mechanic, indicating that introverts have higher levels of enjoyment from it. The finding from QE1 showing higher badges enjoyment for introverts was not replicated. No other significant difference existed.

Table 9. QE2 - t-test Comparing Extraversion and Introversion

\begin{tabular}{|l|c|c|c|c|l|}
\hline & \multicolumn{2}{|c|}{ Extroversion } & \multicolumn{2}{l|}{ Intrave rsion } & Sig. \\
\hline & Me an & Std. dev. & Me an & Std. dev. & \\
\hline Points & 7.42 & 3.24 & 8.66 & 2.51 & 0.108 \\
\hline Reward & 10.42 & 3.85 & 12.34 & 3.14 & 0.046 \\
\hline Badges & 11.77 & 5.14 & 12.91 & 4.45 & 0.370 \\
\hline Progress bar & 13.58 & 3.81 & 14.13 & 3.30 & 0.559 \\
\hline Leaderboard & 8.96 & 3.33 & 8.75 & 2.97 & 0.799 \\
\hline Playfulness & 6.50 & 3.08 & 7.63 & 3.35 & 0.192 \\
\hline
\end{tabular}

Total effects between constructs were extracted in a similar way to the process used in QE1. A comparative table showing these effects between the mechanics and perceived playfulness for each model is presented in Table 10. Several differences between introverts and extraverts are visible in this table, specifically leaderboard - perceived playfulness, which is negative for extraverts and positive for introverts, all badge relations are positive with a stronger total effect for extraverts. Rewards - perceived playfulness is negative for introverts and positive, although not significant for extraverts.

Table 10. QE2 - Comparative Total Effect

\begin{tabular}{|c|c|c|c|c|c|c|c|}
\hline \multirow{2}{*}{\begin{tabular}{|l} 
\\
Badge
\end{tabular}} & \multirow[b]{2}{*}{ Progress bar } & \multicolumn{2}{|c|}{ Entire Sample } & \multicolumn{2}{|c|}{ Introverts } & \multicolumn{2}{|c|}{ Extroverts } \\
\hline & & 0.48 & $* * * *$ & $0.41 *$ & $* * *$ & 0.60 & $* * * *$ \\
\hline & Leaderboard & 0.50 & $* * * *$ & $0.48 *$ & $* * * *$ & 0.62 & $* * * *$ \\
\hline & Playfulness & 0.32 & $* *$ & $0.25 *$ & $* *$ & 0.45 & $* * *$ \\
\hline \multirow[t]{3}{*}{ Points } & Progress bar & -0.01 & & -0.19 & & 0.15 & \\
\hline & Leaderboard & 0.16 & & 0.06 & & 0.24 & $*$ \\
\hline & Playfulness & 0.20 & & $0.51 *$ & $* * *$ & -0.05 & \\
\hline \multirow[t]{3}{*}{ Reward } & Progress bar & 0.24 & & $0.38 *$ & * & -0.02 & \\
\hline & Leaderboard & 0.09 & & $0.31 *$ & $* *$ & -0.03 & \\
\hline & Playfulness & 0.00 & & $-0.49 *$ & $* * * *$ & 0.23 & \\
\hline Progress bar & Playfulness & -0.25 & & $-0.35 *$ & $*$ & 0.14 & \\
\hline Leaderboard & Playfulness & 0.18 & & $0.48 *$ & $* * *$ & -0.37 & $* *$ \\
\hline
\end{tabular}

$* \mathrm{P}<0.1 ; * * \mathrm{p}<0.05 ; * * * \mathrm{p}<0.01 ; * * * * \mathrm{p}<0.001$

To test the significance of the differences between low and high extraversion, a multi-group analysis t-test was performed using same methodology as QE1. The results of this test are presented in Table 11, highlighting the fact that the relations between leaderboard and perceived playfulness is significantly different between introverts (higher) and extraverts (lower), which is in-line with the findings in QE1. Additional significant differences were found between the rewards, points, and progress bar with perceived playfulness, findings which are inconsistent with QE1 findings. 
Table 11. QE2 - Significance of Difference Based on Multi-Group Analysis

\begin{tabular}{|l|l|c|}
\hline \multirow{4}{*}{ Badge } & & $\begin{array}{c}\text { Group difference } \\
\text { (P value) }\end{array}$ \\
\hline \multirow{3}{*}{ Points } & Progress bar & 0.237 \\
\cline { 2 - 3 } & Leaderboard & 0.244 \\
\cline { 2 - 3 } & Playfulness & 0.239 \\
\hline \multirow{2}{*}{ Reward } & Progress bar & 0.221 \\
\cline { 2 - 3 } & Leaderboard & 0.252 \\
\cline { 2 - 3 } & Playfulness & $0.054 \quad *$ \\
\cline { 2 - 3 } & Progress bar & 0.169 \\
\cline { 2 - 3 } & Leaderboard & 0.124 \\
\cline { 2 - 3 } & Playfulness & $0.012 \quad * *$ \\
\hline Progress bar & Playfulness & $0.087 \quad *$ \\
\hline Leaderboard & Playfulness & 0.001 \\
\hline
\end{tabular}

$* \mathrm{P}<0.1 ; * * \mathrm{p}<0.05 ; * * * \mathrm{p}<0.01 ; * * * * \mathrm{p}<0.001$

Finally, predictive relevance of the different models was tested using blindfolding. $Q^{2}$ values were calculated for each of the models and are presented along with their $\mathrm{R}^{2}$ in Table $12 . \mathrm{Q}^{2}$ values were generally higher in QE2 showing medium to high predictive relevance $\left(\mathrm{Q}^{2}\right.$ between 0.15 and 0.35 ) confirming the validity of the structural model.

Table 12. QE2 - $\mathbf{Q}^{2}$ Predictive Relevant Indices and $\mathbf{R}^{2}$

\begin{tabular}{|l|l|l|l|l|l|l|}
\hline & \multicolumn{2}{|c|}{ Full model } & \multicolumn{2}{c|}{ Introvert } & \multicolumn{2}{c|}{ Extrovert } \\
\cline { 2 - 7 } & $\mathrm{R}^{\wedge} 2$ & $\mathrm{Q}^{\wedge} 2$ & $\mathrm{R}^{\wedge} 2$ & $\mathrm{Q}^{\wedge} 2$ & $\mathrm{R}^{\wedge} 2$ & $\mathrm{Q}^{\wedge} 2$ \\
\hline Progress bar & 0.34 & 0.19 & 0.35 & 0.14 & 0.42 & 0.26 \\
\hline Leaderboard & 0.41 & 0.27 & 0.41 & 0.29 & 0.52 & 0.33 \\
\hline Playfulness & 0.21 & 0.15 & 0.42 & 0.30 & 0.38 & 0.31 \\
\hline
\end{tabular}

\section{Discussion}

The objective of this study was to highlight the potential moderating effects that personality has on the playfulness derived from gamification in an educational setting, and specifically extraversion and introversion. Such moderation can potentially explain why different people perceive the same gamification solution in different ways. Realizing these differences can also assist educators in designing solutions that address needs of both extraverts and introverts. Our hypotheses were to check if there are differences between how introverts and extraverts perceive playfulness in a gamified educational setting. While no significant differences in perceived playfulness as a construct were found, the way this playfulness was achieved differed between introverts and extroverts.

The two quasi experiments were carried out under similar contextual conditions, but were different in many aspects. First, QE1 was done without the use of an information system, which meant that the comparative feedback was provided mostly in the class room. Personal feedback was given via email and was not visible by other team mates. In QE2, all feedback was publicly accessible for all class mates and was immediate since it was automated, as opposed to QE1, where it was provided at certain intervals such as class meetings or grading activities.

Another major difference is that QE1 was carried out in a non-competitive environment, whereas QE2 was competitive. Throughout QE2 students expressed their dissatisfaction from the grading scheme presented since it promoted competition among class mates. As a result, they attempted to 
coordinate the results, such that all students complete the course with the same amount of points, turning the competition into a cooperative effort. This meant that in some cases, receiving points or other forms of feedback, which were above what the class decided, was perceived as a negative event by students.

A comparative result of total effects between QE1 and QE2 are presented in Table 13, and the moderations comparison between quasi-experiments can be seen in Table 14 .

Table 13. Comparative Total Effect

\begin{tabular}{|l|l|c|c|c|c|}
\hline \multirow{2}{*}{} & \multicolumn{2}{|c|}{ QE1 } & \multicolumn{2}{c|}{ QE2 } \\
\cline { 3 - 6 } & Badge & Introverts & Extroverts & Introverts & Extroverts \\
\hline & Progress bar & -0.0389 & 0.118 & $0.406^{* * *}$ & $0.5982^{* * * *}$ \\
\hline & Leaderboard & $0.6303^{* * * *}$ & $0.3667^{* * *}$ & $0.4787^{* * * *}$ & $0.623^{* * * *}$ \\
\hline & Playfulness & 0.0739 & 0.0544 & $0.2535^{* *}$ & $0.452^{* * *}$ \\
\hline & Progress bar & $0.274^{*}$ & $0.3151^{* * *}$ & -0.1894 & $0.1524^{*}$ \\
\hline & Leaderboard & 0.1166 & $-0.2308^{*}$ & 0.0565 & $0.2438^{*}$ \\
\hline Reward & Playfulness & 0.1973 & $0.2651^{* *}$ & $0.5138^{* * *}$ & -0.0522 \\
\hline & Progress bar & 0.1283 & $0.3397^{* * *}$ & $0.3812^{*}$ & $-0.0188^{*}$ \\
\hline & Leaderboard & -0.0067 & 0.156 & $0.3105^{* *}$ & -0.0281 \\
\hline Progress bar & Playfulness & 0.1266 & $0.0378^{*}$ & $-0.4941^{* * * *}$ & 0.2332 \\
\hline Leaderboard & Playfulness & $0.3188^{* * *}$ & $0.4628^{* * * *}$ & $-0.3525^{*}$ & 0.1396 \\
\hline
\end{tabular}

$* \mathrm{P}<0.1 ; * * \mathrm{p}<0.05 ; * * * \mathrm{p}<0.01 ; * * * * \mathrm{p}<0.001$

Table 14. Moderating Effects in Both Quasi-Experiments

\begin{tabular}{|l|l|c|c|}
\hline \multicolumn{2}{|l|}{} & QE1 & QE2 \\
\hline Badge & Progress bar & 0.32 & 0.24 \\
\hline & Leaderboard & $0.08^{*}$ & 0.24 \\
\hline & Playfulness & 0.40 & 0.24 \\
\hline & Progress bar & 0.39 & 0.22 \\
\hline & Leaderboard & $0.03^{* *}$ & 0.25 \\
\hline & Playfulness & 0.37 & $0.054^{*}$ \\
\hline & Progress bar & 0.25 & 0.17 \\
\hline & Leaderboard & 0.21 & 0.12 \\
\hline Progress bar & Playfulness & 0.36 & $0.01 * *$ \\
\hline Leaderboard & Playfulness & 0.27 & $0.09 *$ \\
\hline$*$ P $<0.1 ; * *$ \\
\hline
\end{tabular}

$* \mathrm{P}<0.1 ; * * \mathrm{p}<0.05 ; * * * \mathrm{p}<0.01 ; * * * * \mathrm{p}<0.001$

It is rare to have two identical gamification experiences, thus having differences between QE1 and QE2 is not problematic. While the results were similar in direction in most cases, there were some contradictory results between studies, which can be attributed to the different settings between studies.

We found that in both studies there is a significant difference in how leaderboards are related to perceived playfulness. For extraverts, the enjoyment from leaderboards had a negative effect on the perceived playfulness of the entire system. Introverts had significant positive relations in QE2 but not significant in QE1. While this contradicts our third hypothesis of finding a stronger relation for extraverts (Ross, et al., 2003), it can be explained by the offline nature of the competition, 
the leaderboards, and the asynchronous nature of the course (Amichai-Hamburger, et al., 2002). Being top on a leaderboard was enjoyable at the same levels for both types of personality (as seen in Table 3 and Table 9), but since extraverts would prefer to be able to brag about it in real-time and in a face-to-face situation, they perceive it to not be playful, again contradicting H3.

The points relationship with perceived playfulness was significantly different in QE2, with introverts having a strong positive effect, which again contradicts H3. In QE2 points were given for participation in forum activities, which are asynchronous and personal activities, activities that suit the introvert trait much more than extraversion (Lawrence, 1993).

In QE1, the enjoyment from badges was significantly higher for extraverts compared to introverts, and in QE2 it was higher for extraverts, but without statistical significance. H4 expected not to find such moderation; therefore, we can say that in QE1, H4 is not supported. This difference can be explained by the fact that in QE1 badges were given verbally during class time, which is a medium extraverts would feel more comfortable with, unlike in QE2 where they were given automatically and discreetly by the system, which is the case in most automated gamification solutions. In general, the relations between badges and the presentation mechanics and perceived playfulness, was significantly positive and large $\left(\mathbf{R}^{2}\right.$ ranging from $\left.25 \%-62 \%\right)$ for both types of personality, with no significant difference, indicating they are an efficient game mechanic in creating playfulness.

Rewards are artifacts that have actual value to the students unlike badges, which are a virtual form of recognition and have no real value. In QE2, there was a significant difference in the perceived enjoyment from rewards, with a strong negative relation for introverts and a positive yet insignificant relation for extraverts. This is an expected result, and supports H1, based on Gray's theory (Gray, 1970), postulating that extraverts are motivated by rewards, while introverts are motivated by punishments, a finding that was also replicated in a classroom setting (McCord \& Wakefield, 1981). Despite the negative relation between rewards and perceived playfulness for introverts, the enjoyment from rewards in general in QE2 was significantly higher for introverts compared to extraverts.

The total effect between progress and perceived playfulness was positive and not moderated by extraversion in QE1, as expected by $\mathrm{H} 2$, however in QE2 this was not the case $(\mathrm{p}=0.09)$. In QE2, a negative relation existed for introverts, while a positive, but not significant, relation existed for extroverts. This can perhaps be explained by the high relation between rewards and playfulness $(\beta=0.38)$ and the fact that rewards are perceived in a negative manner by introverts. Give the borderline $\mathrm{p}$ value, this should be further explored.

We expected points to be related to leaderboards, but in both studies this was not the case. Instead, points were related to progress bar in QE1 and to perceived playfulness. In QE1 there was no competition, and therefore there was generally a lack of perceived playfulness from leaderboards. In QE2 the competition created a negative atmosphere in class, yet introverts reported very high levels of perceived playfulness as a result of the leaderboard, with a main effect of 0.475 , compared to a negative effect by extraverts -0.372 .

Based on these findings, it is possible to say that an extraversion moderation effect between game mechanics and perceived playfulness exists. This effect may differ from one implementation to another but should be acknowledged and taken into account, when designing educational gamification. Specifically the moderating effect from using leaderboards should be considered, as it was a significant moderator in both studies. 


\section{Conclusion}

Two main contributions are made in this paper. First, we propose a novel way to test the relationships among game mechanics and perceived playfulness, which is missing in current literature. This method can be expanded to include additional game mechanics and provide a better understanding of what creates the perceived playfulness in educational gamification. And second, we highlight the potential risks from applying gamification as a means of increasing student engagement, showing that different personalities may perceive a similar solution in different and even very negative ways.

The key takeaways for educators is that, when using gamification, the common and most straightforward mechanics of leaderboards and points work well for introverts, but can have negative effects on extraverts. Similarly, rewards work well for extraverts and less well for introverts. To achieve overall increased playfulness, a correct combination of mechanics should be used and, if needed, changed throughout the course, to ensure success.

These studies have several limitations that should be acknowledged and further researched. First, the measurement model for the game mechanics was developed from scratch in QE1 and was revised from QE2. While validity and reliability values in QE2 were high and above required values, they require further validation and increased external validity. The classification of participants to extraverts or introverts was done by normalizing data and considering the mean to be the division point. This was carried out due to limited sample size, and in future studies a better classification scheme should be used. Finally, as with every self-reported study, there are many biases in the responses and specifically with gamification, where people are not always conscious about how they will behave when faced with a competitive or a collaborative environment

In future research we plan to include additional personality traits and demographics, such as gender and age, as moderating or controlling variables. In addition, we would like to test the actual usage patterns of students and test them against their self-reported measures, which were used in this study. It is possible that playfulness motivates extraverts and introverts in different ways, or carries different importance levels, which is something that was not considered in this study, and should be tested in future research.

\section{References}

Amichai-Hamburger, Y., Wainapel, G., \& Fox, S. (2002). On the Internet no one knows I'm an introvert: Extroversion, neuroticism, and internet interaction. CyberPsychology \& Behavior, 5(2), 125-128.

Anderson, A., Huttenlocher, D., Kleinberg, J., \& Leskovec, J. (2013). Steering user behavior with badges. Paper presented at the 22nd International Conference on World Wide Web, Rio de Janeiro, Brazil.

Andreev, P., Heart, T., Maoz, H., \& Pliskin, N. (2009). Validating formative partial least squares (PLS) models: Methodological review and empirical illustration. Paper presented at the International Conference on Information Systems (ICIS), Phoenix, AZ.

Antin, J., \& Churchill, E. F. (2011). Badges in social media: A social psychological perspective. Paper presented at the CHI 2011 Gamification Workshop, Vancouver, BC, Canada.

Barata, G., Gama, S., Jorge, J., \& Goncalves, D. (2013). Engaging engineering students with gamification. Paper presented at the 5th International Conference on Games and Virtual Worlds for Serious Applications (VS-GAMES), Bournemouth, UK.

Barrick, M. R., Mount, M. K., \& Strauss, J. P. (1993). Conscientiousness and performance of sales representatives: Test of the mediating effects of goal setting. Journal of Applied Psychology, 78(5), 715.

Brathwaite, B., \& Schreiber, I. (2009). Challenges for game designers. Boston, MA: Cengage Learning. 
Costa, J. P., Wehbe, R. R., Robb, J., \& Nacke, L. E. (2013). Time's up: Studying leaderboards for engaging punctual behaviour. Paper presented at the Gamification 2013, Stratford, ON, Canada.

Denny, P. (2013). The effect of virtual achievements on student engagement. Paper presented at the SIGCHI Conference on Human Factors in Computing Systems, Paris, France.

Deterding, S., Dixon, D., Khaled, R., \& Nacke, L. (2011). From game design elements to gamefulness: Defining gamification. Paper presented at the 15th International Academic MindTrek Conference: Envisioning Future Media Environments, Tampere, Finland.

Deterding, S., Sicart, M., Nacke, L., O'Hara, K., \& Dixon, D. (2011). Gamification. Using game-design elements in non-gaming contexts. Paper presented at the CHI 2011, Vancouver, Canada.

Endler, N. S., \& Parker, J. D. A. (1992). Interactionism revisited: Reflections on the continuing crisis in the personality area. European Journal of Personality, 6(3), 177-198.

Gamification.org. (2012). Game mechanics. Retrieved 4/28/14, from http://gamification.org/wiki/Game_Mechanics

Goldberg, L. R. (1992). The development of markers for the big-five factor structure. Psychological assessment, 4(1), 26-42.

Gray, J. A. (1970). The psychophysiological basis of introversion-extraversion. Behaviour Research and Therapy, 8(3), 249-266.

Hair, J. F., Jr., Hult, G. T. M., Ringle, C., \& Sarstedt, M. (2013). A primer on partial least squares structural equation modeling (PLS-SEM). Thousand Oaks, CA, USA: SAGE Publications.

Hair, J. F., Jr., Ringle, C. M., \& Sarstedt, M. (2011). PLS-SEM: Indeed a silver bullet. The Journal of Marketing Theory and Practice, 19(2), 139-152.

Hakulinen, L., Auvinen, T., \& Korhonen, A. (2013). Empirical study on the effect of achievement badges in TRAKLA2 online learning environment. Paper presented at the Learning and Teaching in Computing and Engineering (LaTiCE), Macau, China.

Hamari, J. (2013). Transforming homo economicus into homo ludens: A field experiment on gamification in a utilitarian peer-to-peer trading service. Electronic Commerce Research and Applications, 12(4), 224-235.

Hamari, J., Koivisto, J., \& Sarsa, H. (2014). Does gamification work? -- A literature review of empirical studies on gamification. Paper presented at the 47th Hawaii International Conference on System Sciences, Hawaii, USA.

Hays, R. T. (2005). The effectiveness of instructional games: A literature review and discussion. Orlando, FL: Naval Air Warfare Center Training Systems Division.

Henseler, J., Ringle, C., \& Sinkovics, R. (2009). The use of partial least squares path modeling in international marketing. Advances in International Marketing (AIM), 20, 277-320.

Hunicke, R., LeBlanc, M., \& Zubek, R. (2004). MDA: A formal approach to game design and game research. Paper presented at the AAAI Workshop on Challenges in Game AI, San Jose, CA.

Huotari, K., \& Hamari, J. (2011). Gamification from the perspective of service marketing. Paper presented at the CHI 2011 Workshop Gamification, Vancouver, Canada.

Judge, T. A., \& Ilies, R. (2002). Relationship of personality to performance motivation: A meta-analytic review. Journal of Applied Psychology, 87(4), 797.

Ke, F. (2009). A qualitative meta-analysis of computer games as learning tools. In R. E. Ferdig (Ed.), Handbook of research on effective electronic gaming in education (Vol. 1, pp. 1-32). Hershey, NY: IGI Global.

Keil, M., Tan, B. C. Y., Wei, K.-K., Saarinen, T., Tuunainen, V., \& Wassenaar, A. (2000). A cross-cultural study on escalation of commitment behavior in software projects. MIS Quarterly, 24(2), 299-325. 
Kim, B., Park, H., \& Baek, Y. (2009). Not just fun, but serious strategies: Using meta-cognitive strategies in game-based learning. Computers \& Education, 52(4), 800-810.

Lawrence, G. D. (1993). People types \& tiger stripes (Vol. 3). Gainesville, FL: Center for Applications of Psychological Type, Inc.

Lee, S. M., \& Chen, L. (2010). The impact of flow on online consumer behavior. Journal of Computer Information Systems, 50(4), 1.

Locke, E. A., \& Latham, G. P. (2002). Building a practically useful theory of goal setting and task motivation: A 35-year odyssey. American Psychologist, 57(9), 705-717.

Locke, E. A., Shaw, K. N., Saari, L. M., \& Latham, G. P. (1981). Goal setting and task performance: 19691980. Psychological Bulletin, 90(1), 125-152.

McCord, R. R., \& Wakefield Jr, J. A. (1981). Arithmetic achievement as a function of introversionextraversion and teacher-presented reward and punishment. Personality and Individual Differences, 2(2), 145-152.

McCrae, R. R., \& Costa, P. T. (1989). Reinterpreting the Myers-Briggs Type Indicator from the perspective of the five-factor model of personality. Journal of Personality, 57(1), 17-40.

McCrae, R. R., \& John, O. P. (1992). An introduction to the five-factor model and its applications. Journal of Personality, 60(2), 175-215.

Moon, J.-W., \& Kim, Y.-G. (2001). Extending the TAM for a world-wide-web context. Information \& Management, 38(4), 217-230.

Narasimhan, N., Chiricescu, S., \& Vasudevan, V. (2011). The gamification of television: Is there life beyond badges? Paper presented at the CHI 2011 Workshop Gamification, Vancouver, Canada.

Ringle, C. M., Wende, S., \& Will, S. (2005). SmartPLS 2.0 (M3) Beta. Hamburg.

Roccas, S., Sagiv, L., Schwartz, S. H., \& Knafo, A. (2002). The big five personality factors and personal values. Personality and Social Psychology Bulletin, 28(6), 789-801.

Ross, S. R., Rausch, M. K., \& Canada, K. E. (2003). Competition and cooperation in the five-factor model: Individual differences in achievement orientation. The Journal of Psychology, 137(4), 323-337.

Ryckman, R. M., Thornton, B., Gold, J. A., \& Collier, S. (2011). Considering competition avoidant individuals via the big five model. Current Research in Psychology, 2(1), 108-114.

Schonfeld, E. (2010). SCVNGR's secret game mechanics playdeck. Retrieved 4/28/14, from http://techcrunch.com/2010/08/25/scvngr-game-mechanics/

Sheldon, L. (2011). The multiplayer classroom: Designing coursework as a game. Boston, MA: Course Technology Press.

Van der Heijden, H. (2004). User acceptance of hedonic information systems. MIS Quarterly, 28(4), 695704.

Vogel, J. J., Vogel, D. S., Cannon-Bowers, J., Bowers, C. A., Muse, K., \& Wright, M. (2006). Computer gaming and interactive simulations for learning: A meta-analysis. Journal of Educational Computing Research, 34(3), 229-243.

Werbach, K., \& Hunter, D. (2012). For the win: How game thinking can revolutionize your business. Philadelphia, PA: Wharton Digital Press.

Yeung, A., Read, J., \& Schmid, S. (2012). Students learning styles and academic performance in first year chemistry. Paper presented at the Australian Conference on Science and Mathematics Education, Sydney, Australia.

Zichermann, G., \& Cunningham, C. (2011). Gamification by design: Implementing game mechanics in web and mobile apps. Sebastopol, CA: O'Reilly Media. 


\section{Appendix A - Game Mechanics Questionnaire}

Table 15 and Table 16 include a translation of the questions used to measure game mechanics used for this research. The original questionnaire was provided in Hebrew (which was the teaching language), and included additional items measuring additional game mechanics not included in the final research.

Table 15 - QE1 Game Mechanics Items

\begin{tabular}{|l|l|}
\hline Construct & Question \\
\hline \multirow{3}{*}{} & I prefer to receive a numeric grade over a pass/fail grade on all tasks in the course \\
\cline { 2 - 3 } & I prefer my homework to be graded (note: homework was mandatory but no grade was \\
provided)
\end{tabular}


Table 16 - QE2 Game Mechanics Items

\begin{tabular}{|c|c|}
\hline Construct & Question \\
\hline \multirow{3}{*}{ 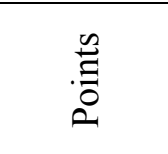 } & In games, I enjoy getting more points than my friends \\
\hline & In games, it is important to me that I get more points than my friends \\
\hline & I prefer games that have a score \\
\hline \multirow{3}{*}{$\begin{array}{l}\mathscr{D} \\
\stackrel{D}{0} \\
\tilde{E} \\
\tilde{D}\end{array}$} & I'm willing to put in extra effort in order to gain a trophy \\
\hline & I'm willing to put in extra effort to get a pretty badge \\
\hline & It is important to me to get as many badges as possible in the course \\
\hline \multirow{3}{*}{ 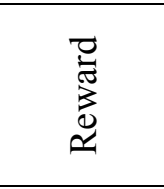 } & I enjoy winning prizes \\
\hline & I will put in extra effort to win a coffee voucher \\
\hline & $\begin{array}{l}\text { When something is been given away at a certain time and place, I will make extra effort to } \\
\text { be there }\end{array}$ \\
\hline \multirow{3}{*}{ 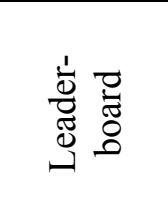 } & Knowing my position compared to other student in the course, stimulates me \\
\hline & It's important for me to know my position compared to other classmates. \\
\hline & A class leaderboard will help me know my position compared to my classmates \\
\hline \multirow{3}{*}{$\begin{array}{l}0 \\
0 \\
0 \\
0 \\
0 \\
0\end{array}$} & It's important for me to know what I need to do to progress \\
\hline & $\begin{array}{l}\text { A progress bar in the course will help me understand where I stand against the expecta- } \\
\text { tions from me }\end{array}$ \\
\hline & $\begin{array}{l}\text { After receiving the "best project of the week " badge, I would put extra effort to keep it } \\
\text { another week }\end{array}$ \\
\hline
\end{tabular}




\section{Appendix B - Five Factor Model Questionnaire}

The following are the 50 item questions used to test the FFM taken from http://ipip.ori.org/New IPIP-50-item-scale.htm. The original questionnaire was provided in Hebrew based on an existing validated translation of these items.

\section{How Accurately Can You Describe Yourself?}

Describe yourself as you generally are now, not as you wish to be in the future. Describe yourself as you honestly see yourself, in relation to other people you know of the same sex as you are, and roughly your same age. So that you can describe yourself in an honest manner, your responses will be kept in absolute confidence. Indicate for each statement whether it is 1. Very Inaccurate, 2. Moderately Inaccurate, 3. Neither Accurate Nor Inaccurate, 4. Moderately Accurate, or 5. Very Accurate as a description of you.

\begin{tabular}{|c|c|c|c|c|}
\hline $\begin{array}{c}\text { Very } \\
\text { Inaccurate }\end{array}$ & $\begin{array}{l}\text { Moderately } \\
\text { Inaccurate }\end{array}$ & $\begin{array}{c}\text { Neither } \\
\text { Accurate } \\
\text { Nor } \\
\text { Inaccurate }\end{array}$ & $\begin{array}{c}\text { Moderately } \\
\text { Accurate }\end{array}$ & $\begin{array}{c}\text { Very } \\
\text { Accurate }\end{array}$ \\
\hline
\end{tabular}

1. Am the life of the party.

2. Feel little concern for others.

3. Am always prepared.

4. Get stressed out easily.

5. Have a rich vocabulary.

6. Don't talk a lot.

7. Am interested in people.

8. Leave my belongings around.

9. Am relaxed most of the time.

10. Have difficulty understanding abstract ideas.

11. Feel comfortable around people.

12. Insult people.

13. Pay attention to details.

14. Worry about things.

15. Have a vivid imagination.

16. Keep in the background.

17. Sympathize with others' feelings.

18. Make a mess of things.

19. Seldom feel blue.

20. Am not interested in abstract ideas.

21. Start conversations.

22. Am not interested in other people's problems.

23. Get chores done right away.
$\mathrm{O}$

$\mathrm{O}$

$\mathrm{O}$

$\mathrm{O}$

$\mathrm{O}$

$\mathrm{O}$

$\mathrm{O}$

O

O

$\mathrm{O}$

O

$\mathrm{O}$

$\mathrm{O}$

$\mathrm{O}$

$\mathrm{O}$

$\mathrm{O}$

O

O

O

O

O

O

O
$\mathrm{O}$

O

O

O

O

O

$\mathrm{O}$

O

O

O

O

O

O

O

O

O

$\mathrm{O}$

O

O

$\mathrm{O}$

O

O

O

\section{O}

O

O

O

$\mathrm{O}$

O

O

$\mathrm{O}$

$\mathrm{O}$

$\mathrm{O}$

O

O

O

O

O

O

$\mathrm{O}$

O

O

O

O

$\mathrm{O}$

$\mathrm{O}$

$\mathrm{O}$

O

O

$\mathrm{O}$

O

$\mathrm{O} \quad \mathrm{O}$

O O

$\mathrm{O} \quad \mathrm{O}$

$\mathrm{O}$
$\mathrm{O}$

$\mathrm{O}$ 
24. Am easily disturbed.

25. Have excellent ideas.

26. Have little to say.

27. Have a soft heart.

back in their proper place.

29. Get upset easily. nation.

31. Talk to a lot of different $\mathrm{O}$

$\mathrm{O}$ people at parties.

32. Am not really interested in

$$
\mathrm{O}
$$

$\mathrm{O}$

$\mathrm{O}$

$\mathrm{O}$

$\mathrm{O}$

O

O

$\mathrm{O}$

$\mathrm{O}$

O

$\mathrm{O}$

$\mathrm{O}$

$\mathrm{O}$

$\mathrm{O}$

$\mathrm{O}$

$\mathrm{O}$

$\mathrm{O}$

$\mathrm{O}$

$\mathrm{O}$

$\mathrm{O}$

$\mathrm{O}$

$\mathrm{O}$

$\mathrm{O}$

$\mathrm{O}$

$\mathrm{O}$

O

$\mathrm{O}$

$\mathrm{O}$ others.

33. Like order.

34. Change my mood a lot.

$\mathrm{O}$

O

$\mathrm{O}$

$\mathrm{O}$

35. Am quick to understand things.

36. Don't like to draw attention

37. Take time out for others.

$\mathrm{O}$

38. Shirk my duties.

$\mathrm{O}$

$\mathrm{O}$

$\mathrm{O}$ swings.

40. Use difficult words.

$\mathrm{O}$

O

O

$\mathrm{O}$

$\mathrm{O}$

$\mathrm{O}$

$\mathrm{O}$

$\mathrm{O}$

$\mathrm{O}$ of attention.

42. Feel others' emotions. $\mathrm{O}$

$\begin{array}{llll}\mathrm{O} & \mathrm{O} & \mathrm{O} & \mathrm{O}\end{array}$

43. Follow a schedule.

44. Get irritated easily.

$\mathrm{O}$

$\mathrm{O}$

$\mathrm{O}$

$\mathrm{O}$

$\mathrm{O}$

$\mathrm{O}$

$\mathrm{O}$

$\mathrm{O}$

$\mathrm{O}$ things.

46. Am quiet around strangers.

O

$\mathrm{O}$

O

$\mathrm{O}$

$\mathrm{O}$

$\mathrm{O}$

$\mathrm{O}$

$\mathrm{O}$

$\mathrm{O}$

$\mathrm{O}$

O

O

$\mathrm{O}$

$\mathrm{O}$
$\mathrm{O}$
$\mathrm{O}$
$\mathrm{O}$
$\mathrm{O}$

$\mathrm{O}$ 


\section{Biographies}

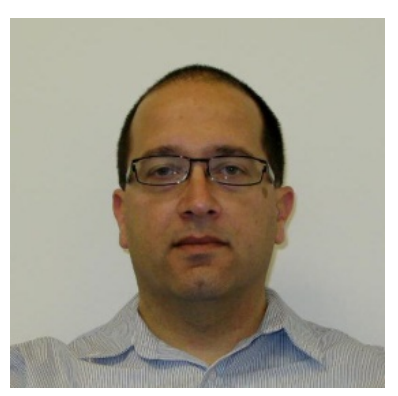

David Codish is a $\mathrm{PhD}$ candidate at the Industrial Engineering and Management at department at Ben-Gurion University, Israel. For the past 20 years, David managed several Information Systems organizations for a variety of hi-tech organizations and is now focusing most of his time on research. His key research area is gamification and its inclusion in various information systems as a means of making tedious tasks more fun, increasing user acceptance and achieving higher performance.

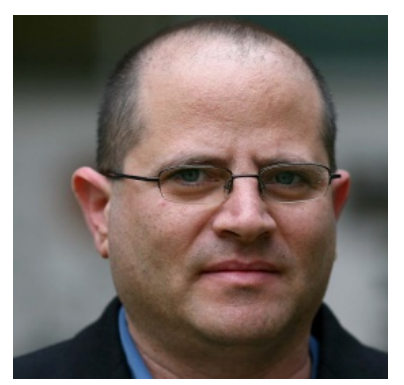

Gilad Ravid is a senior faculty member in Information Systems at the Department of Industrial Engineering and Management, Ben-Gurion University of the Negev, Israel. His Ph.D., titled "Information Sharing With CMC in Small Groups: Communication Groups and Tasks " is from Hafia University, his MBA from the Hebrew University, and his B. Sc. in Agricultural Engineering from the Technion. He was a postdoctoral fellow at the Annenberg Center for Communication, University of Southern California, Los Angeles. Dr. Ravid's main interests are focused on the relationship between social structure and human behavior, games and gamification and computer-mediated communication systems. His work includes such research as information overload phenomena, social structure in web-based educational forums, wiki-based education and wikipedia as a social space, celebrity formation, the "social structure " of lightning synchronization, civil information needs and information sharing in groups, learning with games and gamification solutions. He has published in top peer-reviewed journals including Information Systems Research, First Monday, and Information Systems Journal. 